\title{
EDUCAÇÃO AMBIENTAL E INCLUSÃO DE TECNOLOGIA SOCIAL PARA SANEAMENTO BÁSICO EM PROPRIEDADES DE AGRICULTORES FAMILIARES
}

\author{
Eliandra Gomes Marques ${ }^{1}$, Dionísio Link ${ }^{2}$, Luiz Felipe Gomes Uberti ${ }^{3}$, Toshio Nishijima ${ }^{4}$ \\ ${ }^{1}$ Educadora com especialização em Educação Ambiental, em Mídias na Educação e em Gestão Educacional pela \\ UFSM. egomesmarques@gmail.com. \\ ${ }^{2}$ Agrônomo, Dr., Professor Titular do Centro de Ciências Rurais da UFSM. dlink@yahoo.com.br. \\ ${ }^{3}$ Zootecnista com especialização em Educação Ambiental pela UFSM. fuberti@oi.com.br. \\ ${ }^{4}$ Engenheiro agrônomo, Dr. Professor Adjunto do Centro de Ciências Rurais da UFSM. toshionishijima@gmail.com.
}

http://dx.doi.org/10.5902/223613085916

\section{RESUMO}

Nesse artigo são apresentados os resultados de um trabalho de pesquisa-ação em Educação Ambiental desenvolvido com agricultores familiares de comunidades rurais do município de Bandeirante/SC em 2010. Por essa pesquisa estar atrelada a um processo educativo, tem-se como objetivo propor estratégias de ações de Educação Ambiental e de inclusão de tecnologia social para saneamento básico em propriedades de agricultores familiares do município de Bandeirante/SC. As reflexões apresentadas ressaltam a importância do trabalho coletivo bem como da interação dialógica entre os envolvidos, pois se acredita que, através de mudanças cotidianas, a qualidade de vida desses agricultores familiares e a relação que os mesmos têm com o meio em que vivem foi favorecida, contribuindo para o desenvolvimento rural sustentável.

Palavras-chave: educação ambiental; tecnologia social; agricultura familiar; saneamento básico.

\section{ABSTRACT ENVIRONMENTAL EDUCATION AND INCLUSION OF SOCIAL TECHNOLOGY FOR SANITATION IN FAMILY FARMERS PROPERTIES}

This article presents the results of an action research work on environmental education developed in 2010 with family farmers from rural communities in Bandeirante, a town located in the State of Santa Catarina, Brazil. Since this research is closely related to an educational process, its aim is to propose strategies for environmental education activities and inclusion of social technology for sanitation on family farmers properties in Bandeirante. The reflections presented here highlight the importance of collective work and dialogical interactions among those involved. This approach was chosen because it is believed that the quality of life of family farmers and their relationship with their environment has been favored, thus contributing to sustainable rural development.

Keywords: environmental education; social technology; family agriculture; sanitation. 


\section{INTRODUÇÃO}

Este artigo é um recorte da monografia "Educação Ambiental e Tecnologia Social: juntas por um desenvolvimento rural sustentável" apresentada ao Curso de Especialização em Educação Ambiental da Universidade Federal de Santa Maria - UFSM. A presente pesquisa está alicerçada no convívio de quatro anos com trabalhos e acompanhamentos a grupos voltados à agricultura familiar no município de Bandeirante, pertencente à região do extremo oeste do Estado de Santa Catarina, Brasil.

Essa região - colonizada na década de 1940 por famílias rurais vindas do Rio Grande do Sul, é basicamente formada pela agricultura familiar que se caracteriza pela diversificação da produção, no entanto aproximadamente $80 \%$ das famílias tem como a principal atividade econômica a produção de leite, que é responsável pela sua renda mensal; a mão-de-obra é familiar.

O município dista $700 \mathrm{~km}$ da capital catarinense, Florianópolis, e está a 517 metros de altitude em relação ao nível do mar e sua posição está determinada pelo paralelo de 26046'07" graus de latitude sul e pelo meridiano de $53^{\circ} 08^{\prime} 16$ de longitude. A área do município compreende um território de $146 \mathrm{Km}^{2}$. Seus limites são: ao norte, o município de Paraíso; ao sul, Belmonte; a leste, São Miguel do Oeste; e a oeste a República Argentina, por está razão é um município de fronteira (PREFEITURA MUNICIPAL DE BANDEIRANTE, 2010).

Quanto aos aspectos demográficos, a população residente no ano 2010 está constituída por 2.906 pessoas; sendo que delas a maior parte mora na área rural 67,93\%, consequentemente a taxa de urbanização é de $32,07 \%$ uma das mais baixas da região (IBGE, 2010). No que se refere aos rendimentos e distribuição de renda, considerando que a mão-de-obra é familiar, a renda mensal é de aproximadamente 1,5 salário mínimo por família sendo a bovinocultura de leite a principal atividade seguida do cultivo de milho e fumicultura.

Em relação aos níveis de saneamento básico tanto na cidade como no campo são muito baixos fato que compromete a qualidade de vida da população do município. A coleta de "lixo" na zona urbana é feita três vezes por semana, fato que na zona rural ocorre esporadicamente, no máximo uma vez ao ano. Já o abastecimento de água atinge $100 \%$ dos domicílios. 0 mesmo não se aplica ao esgotamento sanitário que tem sua aplicação em apenas $1 \%$ dos domicílios, sendo que a maioria desses imóveis dispõe de fossas rudimentares com 15\% de efeito despoluitivo.

Esses dados são consequências reais do atual modelo capitalista de desenvolvimento que "produz exclusão social e miséria por um lado, consumismo, opulência e desperdício, por outro. Ambos causam degradação ambiental e, em consequência, perda da qualidade de vida." (DIAS, 2004, p. 33). Além da instabilidade econômica, a forma atual do capitalismo global é insustentável dos pontos de vista ecológico e social e por isso não é viável para a sociedade atual.

Pensa-se, sobretudo, em desenvolvimento rural, mas os agricultores familiares vivem em um ilusório desenvolvimento que se diz sustentável e que na prática é socialmente excludente, ecologicamente incorreto e economicamente inviável. Rattner (2009) converge com essa ideia e destaca que "o modelo de desenvolvimento do mundo não é sustentável" (RATTNER, 2009, p. 1971).

Sob esse aspecto, Capra (2005, p. 155) escreve que "o capitalismo global fez aumentar a pobreza e a desigualdade social não só através da transformação das relações entre o capital e o trabalho, mas também pelo processo de exclusão social" uma vez que é latente a falta de percepção dos indivíduos sobre esse modelo imposto e que procura fechar saídas para alternativas desses excluídos. 
Pisoni (2009) aponta que esse modelo trouxe problemas como a dependência dos agricultores familiares e sua história de marginalização ao longo dos anos.

Frente a todas as consequências negativas que esse modelo de desenvolvimento trouxe para a agricultura familiar do ponto de vista social, econômico e ambiental, objetiva-se um desenvolvimento que possa contribuir com o agricultor familiar tornando-o sujeito autônomo em busca da melhoria de sua qualidade de vida (PISONI, 2009, p.16).

Segundo a autora, há esperança de que esse quadro de empobrecimento dos agricultores familiares em relação ao modelo de desenvolvimento adotado pela sociedade seja transformado. E tal mudança ocorre a partir da Educação Ambiental, pois ela surge da necessidade de pensar um novo modelo de desenvolvimento que seja sustentável cujas relações sejam estabelecidas equilibradamente entre homem, sociedade e natureza.

Sob esse aspecto, Dias (2004) alerta que a Educação Ambiental é o elemento fundamental para a implantação desse novo modelo, pois "acredita-se que o Desenvolvimento Sustentável seja a forma mais viável de sairmos da rota da miséria, exclusão social e econômica, consumismo, desperdício e degradação ambiental em que a sociedade humana se encontra." (DIAS, 2004, p. 64). Daí a necessidade de haver uma educação transformadora, ética, dialógica, crítica, participativa e democrática que estimule os sujeitos ao exercício pleno e consciente de seus direitos e deveres.

Percebendo-se a emergência de ações de revitalização da agricultura familiar em Bandeirante e na ótica de efetivar um modelo de desenvolvimento sustentável, um grupo de agricultores familiares juntou esforços coletivos e decidiu mobilizar-se e captar recursos para implantar saneamento básico em suas comunidades.

No projeto, denominado "Promovendo a Saúde Rural", convênio firmado entre o Ministério da Ciência e Tecnologia - MCT, por meio da Secretaria de Ciência e Tecnologia para a Inclusão Social - SECIS, e a Prefeitura Municipal de Bandeirante, foi adotada a tecnologia social "reator anaeróbio com recheio de bambu" aliada a ações e práticas de Educação Ambiental.

Diante da realidade do contexto local, esta pesquisa se justifica em propor soluções para minimizar os impactos negativos ocasionados pelo Homem ao meio ambiente por meio de adoção de tecnologia social para o tratamento de dejetos domésticos em propriedades de agricultores familiares aliada a ações de Educação Ambiental.

O processo de investigação da realidade sócio-ambiental desencadeado por este estudo tem como tema o "saneamento no meio rural", tema este que se tornou um meio facilitador para a introdução da educação ambiental.

Como essa pesquisa está articulada a um processo educativo, o tema mobiliza todos os envolvidos nessa realidade investigada para uma compreensão do meio que os cerca. Assim, o objetivo geral da pesquisa é propor estratégias de ações de Educação Ambiental e de inclusão de tecnologias sociais para saneamento básico em propriedades de agricultores familiares do município de Bandeirante/SC.

Os objetivos específicos são: (i) sensibilizar as famílias rurais para que elas se percebam integrantes, dependentes e agentes transformadoras do ambiente, identificando seus elementos e as interações entre eles; (ii) articular ações sociais e ambientais, integrando o saber científico ao conhecimento popular baseado nos princípios da educação popular; (iii) sensibilizar, estimular e formar mudanças nas famílias agricultoras em relação à recuperação, à preservação e à proteção 
ambiental; (iv) e capacitar os atores locais no emprego e gestão participativa de tecnologia social para tratamento de dejetos domésticos em propriedades de agricultores familiares.

A escolha metodológica, que norteia essa pesquisa, está focada na pesquisa-ação, devido ao caráter específico de investigação centrado em questões e/ou preocupações de um determinado contexto e pela construção coletiva em suas trocas de saberes, conhecimentos e experiências, pois as comunidades rurais de Bandeirante apresentam características peculiares como: baixa participação dos agricultores familiares na solução dos problemas comuns, individualismo nas relações sociais, não responsabilização em relação à realidade sócio-ambiental, baixo índice de escolaridade, pouco acesso à informação.

\section{TECNOLOGIA SOCIAL PARA SANEAMENTO BÁSICO NO MEIO RURAL}

Apesar do avanço tecnológico e de pesquisas que contribuíram para o progresso social no Brasil, as informações que indicam as condições de saneamento básico, tanto na cidade como no campo, são ainda assustadoras, dado que se torna até um aspecto paradoxal quando se relaciona abastecimento de água e rede coletora de esgoto.

Esse déficit de saneamento básico tem consequências graves para a qualidade de vida da população, principalmente àquelas mais pobres distribuídas em pequenas vilas e bairros e até em comunidades rurais.

Por saneamento básico compreende-se a forma de controlar os fatores que afetam o meio ambiente, trazem prejuízos à saúde e, em consequência, reduzem o desenvolvimento de uma comunidade. É o que destacam Carvalho e Oliveira (2004, p. 13) que "o saneamento é uma das formas de contribuir para a manutenção do equilíbrio a natureza e, portanto, para a própria sobrevivência do ser humano e de todos os recursos e elementos indispensáveis à vida humana.". São medidas que protegem e recuperam a saúde coletiva e propiciam uma motivação da população; logo exercendo benefícios positivos ao bem-estar social e ambiental.

Diante disso, dentre as preocupações de Dias (2004, p. 52) figura a defesa de que se reconhece "o grau de evolução de uma comunidade pela forma como ela trata seus recursos hídricos e seu lixo". Ainda o autor traz à tona dados alarmantes sobre a realidade no Brasil onde "cerca de 88 milhões de brasileiros ainda vivem em domicílios que não têm sistemas de coleta de esgoto sanitário" (DIAS, 2004, p. 52).

Sabe-se do impacto negativo que causa ao meio o lançamento inadequado de rejeitos domésticos, pois comprometem os sistemas naturais e antrópicos. Sob esse aspecto, Tonetti e outros pesquisadores (2010) relatam que a maioria da população que vive em comunidades rurais não dispõe de sistemas de coleta e tratamento de esgoto doméstico de modo que acabam "lançando os esgotos diretamente nos corpos hídricos." (TONETTI et al., 2010, p. 227).

Silva e Nour (2005) também apontam essa realidade no meio rural. Segundo eles, há,

De modo geral, pouca atenção ao tratamento de efluentes líquidos gerados nas propriedades rurais, principalmente os esgotos de origem sanitária que, mesmo não apresentando concentração elevada de compostos poluidores, tem quantidade considerável lançada sem o devido tratamento nos corpos d'água mais próximos da propriedade (SILVA; NOUR, 2005, p. 269). 
Para estes pesquisadores o tratamento dos dejetos domésticos e águas residuais no meio rural ainda são incipientes. E por desconhecem o uso de técnicas simplificadas para o tratamento de esgoto que se apropriam às necessidades rurais é que os pesquisadores vem há anos desenvolvendo pesquisas sobre tecnologias de saneamento básico que exijam pouca manutenção e baixo custo de instalação e operação.

Dentre as tecnologias para saneamento básico destaca-se o reator anaeróbio com recheio de bambu. É uma tecnologia social desenvolvida e validada pela Faculdade de Engenharia Civil, Arquitetura e Urbanismo da Universidade Estadual de Campinas - UNICAMP, e se constitui numa tecnologia de baixo custo, economicamente viável e ecologicamente correta. A opção em tomar essa tecnologia foi devido aos anos de pesquisa sobre seu funcionamento e da credibilidade que a mesma ofereceu já vir sendo implantada em outras localidades rurais, especialmente em Santa Catarina.

Contudo, para minimizar os agravantes causados pela falta de saneamento básico, a aplicabilidade de uma tecnologia social somente tem resultados positivos se estiver aliada a um processo educativo. Por isso que ações em Educação Ambiental auxiliam na disseminação de tecnologias sociais e na efetivação de desenvolvimento sustentável, trazendo melhor qualidade de vida às famílias rurais, as quais se encontram desprovidas de políticas públicas voltadas para o saneamento. Essas ações devem ser contínuas e permanentes, por isso há várias estratégias de mobilização, sensibilização e conscientização.

Indicada para locais que não dispõe de rede de coleta, essa tecnologia social se insere nas comunidades rurais: (i) através de informação oral e escrita, reuniões e visitas domiciliares; (ii) pelo envolvimento dos agricultores familiares na implantação da tecnologia social; (iii) pela manutenção e operação da tecnologia social pelos próprios agricultores.

Desse modo, tornou-se necessário conscientizar as famílias agricultoras quanto aos danos ambientais causados ao meio. Nesse processo de desconstrução de uma percepção fundada no consumismo e na ocupação e uso desordenado dos recursos do meio ambiental é perspicaz que a educação ambiental deva estar inserida para que gere uma ação-reflexão-ação de cada indivíduo.

Corroborando com essa ideia, Freire (2002) aponta que não existe conscientização sem práxis transformadora da realidade. Este processo se caracteriza pelo estabelecimento maduro do diálogo, pela abertura ao novo, construído sobre o que é válido do velho. Segundo o educador popular, a conscientização é uma ação permanente que se encarna na práxis e não se cristaliza na burocratização.

Por isso, a educação é um instrumento indispensável para a sustentabilidade. Logo, não se pode ter uma boa qualidade de vida, sem informações e metodologias participativas básicas a respeito de práticas essenciais para a saúde.

Todavia, para levar a efeito esse mister, sabe-se que antes de tentar sugerir o emprego de tecnologia social para saneamento básico é preciso vencer preconceitos e esclarecer os agricultores familiares sobre a importância de inserir hábitos de higiene no cotidiano e também torna-se necessário conscientizá-las quanto aos danos causados ao meio-ambiente e à sua própria saúde devido ao uso de fossas e sanitários rudimentares.

É neste processo de amadurecimento da consciência que a educação exerce um papel decisivo por estar conjugada com o processo de mudança social (Freire, 1981), pois "ninguém educa ninguém, os homens aprendem comunitariamente" (FREIRE, 2005, p. 68).

Nessa mesma concepção, Morin (2003) destaca que:

A complexidade é a união entre a unidade e a multiplicidade. Como os desafios da complexidade nos confrontam cada vez mais e de maneira cada vez mais inelutável é 
fundamental que a educação promova a "inteligência geral" apta a referir-se ao complexo, ao contexto, de modo multidimensional e dentro da concepção global (MORIN, 2003, p. 38).

Nesse sentido, pela Educação Ambiental é possível que o Homem tenha percepção das ameaças construídas por ele mesmo e que proponha soluções em prol da promoção da sustentabilidade e da restauração de níveis satisfatórios de qualidade de vida, pois, segundo Freire (1980), quando o indivíduo começa a refletir sobre seu mundo está realizando o exercício de conscientização.

A abordagem acerca da leitura que o Homem passa a ter de seu entorno e de si mesmo é o caminho para a sustentabilidade, justificando, assim, o que Teixeira (2007) coloca sobre o entendimento da Educação Ambiental. Para o autor, a Educação Ambiental deve ser percebida:

Como um conjunto de ensinamentos teóricos e práticos com o objetivo de levar à compreensão e de despertar a percepção do indivíduo sobre a importância de ações e atitudes para a conservação e a preservação do meio ambiente, em benefício da saúde e do bem-estar de todos (TEIXEIRA, 2007, p. 25).

Assim, ações práticas e teóricas de Educação Ambiental devem estar no dia-a-dia, em casa, no trabalho, nas ruas da cidade, nos clubes, na escola, nas comunidades rurais e em nos próprios sujeitos, pois, nesses contextos, fica evidenciada a importância do papel da Educação Ambiental no despertar da consciência para a cidadania. A manifestação dessa percepção é sinal de que se está em equilíbrio interior e exteriormente.

\section{A PESQUISA-AÇÃO EM EDUCAÇÃO AMBIENTAL}

A pesquisa-ação foi a metodologia adotada nesse trabalho por configurar uma importante abordagem: a de que o pesquisador passa de observador a participante do processo de mudança, ou seja, como educador ele passa a ser um facilitador de um processo educativo. Nesse caso, o pesquisador desempenha dois papéis cujas finalidades são a de agir conjuntamente para solucionar ou minimizar um problema e a de contribuir para a fixação dos conhecimentos na prática da situação observada. Por isso que nesse tipo de investigação não há neutralidade até porque o papel do pesquisador é também de participante nas ações.

Como importante característica da pesquisa-ação está o processo integrador entre pesquisa, reflexão e ação, sendo que a pesquisa e a ação podem e devem caminhar juntas quando se pretende a transformação da prática num determinado contexto social.

Thiollent (1997) descreve que:

A pesquisa-ação é um tipo de pesquisa social com base empírica que é concebida e realizada em estreita associação com uma ação ou com a resolução de um problema coletivo e na qual os pesquisadores e os participantes representativos da situação ou do problema estão envolvidos de modo cooperativo ou participativo. (THIOLLENT, 1997, p. 14).

Daí se configura o caráter cooperativo e colaborativo dos participantes, pois eles devem intervir coletivamente na ação em todas as suas fases, o que instiga refletir sobre a possibilidade como práxis investigativa da pesquisa-ação. 
Igualmente, a organização de grupos com o qual se pretende desenvolver o processo investigativo implica que os envolvidos devem estar cientes de que terão que intervir em todas as etapas do processo, assim como devem ter disponibilidade e comprometimento. Por isso, eles devem, organizados coletivamente, ter objetivos e metas comuns e estar interessados em um problema que emerge em seu meio.

Para tanto, garantir mudanças num determinado contexto, é preciso comprometimento social. Sob esse aspecto, Jacobi (2003) expressa que:

Há uma demanda atual para que a sociedade esteja mais motivada e mobilizada para assumir um papel mais propositivo, bem como seja capaz de questionar, de forma concreta, a falta de iniciativa do governo na implementação de políticas ditadas pelo binômio da sustentabilidade e do desenvolvimento num contexto de crescente dificuldade na promoção da inclusão social (JACOBI, 2003, p. 192).

Nessa perspectiva é que eclode um conjunto de valores como a construção de relações democráticas e a participação dos sujeitos quando a busca de transformação é fruto da organização e de condições de auto-formação e emancipação dos sujeitos. Para Gamboa (1982, p. 36), a pesquisa-ação "busca superar, essencialmente, a separação entre conhecimento e ação, buscando realizar a prática de conhecer para atuar". Buscam-se as explicações dos próprios participantes que se encontram em situação de investigador.

Dentre os aspectos metodológicos da pesquisa-ação, destacam-se: (i) que deve haver interação entre pesquisador e pessoas implicadas na situação investigada, pois, por meio do diálogo, é possível estabelecerem a ordem de prioridades dos problemas a serem pesquisados e das soluções a serem encaminhadas sob forma de ação concreta; (ii) que o objeto de investigação é constituído pelo coletivo que se identifica com a situação-problema que outros também se encontram e juntos resolvem ou esclarecem os problemas e a situação em que se encontram; (iii) que deve haver o acompanhamento das decisões, das ações e das atividades dos envolvidos na situação; (iv) que o conhecimento de mundo dos envolvidos no processo seja levado em conta.

Sobre a pesquisa-ação em Educação Ambiental, Tozzoni-Reis (2005, p. 273) destaca que a metodologia está centrada em três "práticas" que se articulam entre si: a produção de conhecimento, ação educativa e a participação dos envolvidos, tomando, como ponto de partida, um problema existente e detectado pelas equipes. Essa postura em relação à metodologia da pesquisa-ação se configura em uma metodologia de caráter formativo e emancipatório.

Para discorrer sobre a metodologia que delineia esse trabalho investigativo, optou-se por utilizar as fases da pesquisa-ação, segundo Thiollent (1997, p. 44), descritas a seguir: fase exploratória, fase principal, fase de ação e fase de avaliação.

A fase exploratória considera as ações como alternativas para resolver o problema. Para a análise situacional se faz um diagnóstico visando reconhecer o contexto da pesquisa, das práticas, dos indivíduos envolvidos e de suas necessidades e se planejam ações para resolver ou minimizar problemas comuns.

Paralelamente, monta-se o projeto para monitorar e avaliar a situação e planejar a ação para promover uma mudança adequada da prática, bem como a formação de equipes comprometidas para que na próxima fase, a principal, os educadores iniciem a prática através de atividades pontuais que guiarão as ações durante todo o processo de intervenção. 0 planejamento é parte importante por estarem concentradas ações, roteiros, metodologias, projetadas pelas equipes. 
Importante ressaltar que, na fase principal, há uma equipe permanente que tem poder de decisão na definição de temas prioritários a serem investigados; na coordenação de atividades dos grupos e nas ações de formação; na elaboração da problemática; na interpretação dos dados; no acompanhamento das ações implementadas e avaliação de resultados e na divulgação dos mesmos.

A fase de ação, como o próprio nome indica, é a de execução das ações, sendo que se faz um roteiro com a seleção das ações. Também se faz uma reflexão sobre a prática educativa de cada ação executada que é possibilitada por meio do desenvolvimento de dinâmicas coletivas que permitam o estabelecimento de referências contínuas e evolutivas com os atores envolvidos, no sentido de apreensão dos significados construídos e em construção.

A última fase do processo de pesquisa-ação é a avaliação onde são apresentados os resultados das ações no contexto organizacional da investigação e suas consequências de modo que possam ser extraídos ensinamentos úteis para continuar a experiência em outros contextos. A despeito do retorno das informações aos participantes, Hall (1981) destaca:

A informação é devolvida ao povo, de onde a mesma surgiu bem como na linguagem e na forma cultural daquele ambiente; o povo e o movimento de base passam a estabelecer o controle do trabalho; as técnicas de pesquisa tornam-se acessíveis ao povo; um esforço consciente é necessário para manter o ritmo da ação-reflexão do trabalho; aprender a escutar e a ciência tornam-se partes do dia-a-dia da população (HALL, 1981 apud MELO NETO, s.d, p. 3).

Os resultados são devolvidos à comunidade pesquisada sob a forma de produto para que possa ser analisada, refletida entre todos os envolvidos. Isso remete que a pesquisa-ação requer ação conjunta entre pesquisador-pesquisados tanto na pesquisa quanto na prática.

\section{EDUCAÇÃO AMBIENTAL E DESENVOLVIMENTO RURAL SUSTENTÁVEL}

Para serem apresentados os resultados e discussões das etapas das ações educativas realizadas com agricultores familiares durante os meses de agosto a outubro de 2010, adotaramse as divisões da pesquisa-ação propostas por Thiollent (1997) para descrever a práxis dessa investigação.

\section{Análise situacional}

A análise situacional compreendeu uma abordagem metodológica que se incluíram visitas e contato com as famílias vinculadas à $\mathrm{ADM}^{1}$; aplicação de entrevista semi-estruturada e aberta; cadastro de famílias interessadas em participar do projeto; registros fotográficos dos locais de uso de fossas e outros métodos rudimentares de dejetos domésticos para compor um dossiê com as potencialidades e problemas de cada família, de modo que se possa ter um diagnóstico da realidade local.

Para o diagnóstico e identificação das famílias, foram ocupados dados levantados pelo projeto Microbacias 2 que das 213 famílias agricultoras entrevistadas, 45\% delas ainda possuía privadas e $55 \%$ tinha banheiro em suas casas, porém sem fossa séptica, apenas com tratamento rudimentar de dejetos por meio de poço negro. Nesse mesmo levantamento examinou-se que

\footnotetext{
${ }^{1}$ Abreviatura de "Associação da Microbacia"dada às associações de agricultores familiares em Santa Catarina em virtude do projeto Microbacias 2 . http://cascavel.ufsm.br/revistas/ojs-2.2.2/index.php/remoa
} 
29\% das propriedades não dispunham de água para consumo humano e dessedentação durante algum período do ano e $71 \%$ das famílias possuíam água durante todo o ano. Quanto aos tipos de fontes de água para consumo, os mesmos distribuíam-se da seguinte maneira: $31 \%$ das famílias tinham fontes sem nenhum tipo de proteção, 33\% apenas coberta, $8 \%$ revestida com tubos de concreto e cobertas e $\mathbf{2 8 \%}$ com fonte tipo caxambu.

Essa situação, com o passar do tempo, por meio de apoio do projeto Microbacias 2 e através de outras políticas públicas acessadas pelo município, foi sendo alterada. No entanto, os problemas de saneamento de dejetos domésticos pouco modificaram o cenário rural.

Em levantamento sobre as propriedades familiares rurais, foi detectado lançamento inadequado de rejeitos de esgoto doméstico e de águas residuais de pias e tanques de lavar roupas diretamente no solo; algumas fossas negras estavam com sua capacidade esgotada e até descobertas ocasionando perigo às pessoas e animais domésticos, além de oferecerem ambiente propício na proliferação de vetores.

O resultado desse manejo inadequado de resíduos causa impacto negativo ao meio ambiente, principalmente na contaminação de recursos hídricos como o lençol freático, nascentes e fontes d'água, diretamente no solo. Aliás, em muitas propriedades, foi possível constatar a presença de riachos e sangas próximos da habitação como também a declividade do relevo propiciou ainda a degradação do meio ambiente.

\section{Projeto "Promovendo a Saúde Rural”}

O projeto "Promovendo a Saúde Rural" teve suas ações executadas nos meses de agosto a dezembro de 2010. Porém a história desse projeto, cujo objeto é saneamento básico no meio rural por meio de emprego de tecnologia social, inicia no ano de 2007, quando um grupo de agricultores familiares vai em busca de alternativa para implantar saneamento básico para tratamento de dejetos domésticos em suas comunidades.

As famílias, na época 13, ficaram descontentes em não poder construir uma fossa séptica em suas propriedades porque não havia mais recurso disponível no Microbacias 2 para esse fim. No entanto, esse grupo foi orientado que sua associação podia estar solicitando recursos junto ao governo federal. Para isso solicitaram ao seu técnico-facilitador e à autora dessa pesquisa a elaboração de um projeto que contemplasse essa demanda.

Por ser uma associação, os critérios estabelecidos pelo Sistema de Convênios do governo federal - SICONV, inviabilizam repasse de materiais permanentes, somente custeio, fato que gerou perda do recurso. Mesmo com essa limitação, os agricultores dialogaram com a Prefeitura de Bandeirante para que se apresentasse como proponente do projeto a qual aceitou devido à importância da organização desses agricultores, logo já encaminhando a documentação exigida para o convênio. Mas, por motivos de a Prefeitura estar com pendências de certidões no SIAFI/CAUC ${ }^{2}$, novamente não houve convênio.

O grupo de agricultores familiares insistiu e, no ano de 2008, outra vez foi submetida a proposta, porém se teve que ampliar o número de beneficiários por conta de um decreto federal onde instituições públicas deveriam firmar convênios com o Estado no valor mínimo de R\$

\footnotetext{
${ }^{2}$ SIAFI - Sistema Integrado de Administração Financeira do Governo Federal é uma ferramenta poderosa para executar, acompanhar e controlar com eficiência e eficácia a correta utilização dos recursos da União. Portal de acesso <http://consulta.tes ouro.fazenda.gov.br/entesbloqueados/index.asp>.

O CAUC disponibiliza informações quanto ao cumprimento das exigências fiscais de entes federados a partir da inserção do CNPJ. http://cascavel.ufsm.br/revistas/ojs-2.2.2/index.php/remoa
} 
100.000,00 (cem mil reais). Como já se tinha dados levantados sobre a situação do saneamento em outras comunidades rurais do município, foi fácil inserir novas famílias.

Dessa vez os trâmites para aprovação do projeto tomou menos tempo, mas, por ser uma época de transição de governos municipais, e o recurso já tinha sido disponibilizado em conta bancária específica do convênio, esbarrou-se na continuidade de projetos de governo municipal antecessor, e, devido à vontade político-partidária teve-se que esperar de 2009 até agosto de 2010 para que o gestor municipal entendesse a necessidade de executar o projeto por sua história.

Logo que todos os entraves foram eliminados, começou-se a divulgação do projeto à comunidade geral, técnicos do município, gestores e beneficiários, sua apresentação, e passou-se para a realização de ações prático-educativas de Educação Ambiental.

\section{Ações prático-educativas}

As ações de Educação Ambiental foram realizadas dentro do princípio da pesquisa-ação e da educação popular, no sentido de mobilizar e sensibilizar agricultores familiares para a viabilização do projeto e possibilitá-los outro olhar sobre o meio do qual fazem parte. Foram realizadas reuniões em duas comunidades - Linha Gaspar e Linha Prata, onde se reuniram as famílias agricultoras beneficiárias do projeto. Optou-se por reunir outras comunidades abrangidas pelo projeto (Linhas Aparecida, Riqueza do Oeste e Adolfo Ziguelli) a essas localidades devido à proximidade e para integrar as comunidades.

Das dez comunidades rurais existentes no município, apenas cinco delas foram contempladas no projeto por que o recurso era limitado e priorizaram-se comunidades cujos agricultores mostraram interesse em ser beneficiários do projeto.

Iniciou-se fazendo uma apresentação histórica sobre o projeto, desde a ideia geradora até a liberação de recursos para, inclusive, estar cumprindo essa meta; após, foram abordadas questões sobre higiene e saúde por meio de dados coletados no diagnóstico do local e também os disponibilizados por fontes reconhecidas, bem como os aspectos sobre a realidade do saneamento no Brasil, como forma de conscientização quanto à problemática.

O diálogo foi o meio facilitador entre as exposições trazidas pelos educadores e os beneficiários, bem como o uso de metodologias participativas. Também para o planejamento das ações posteriores, contou-se com a participação de todos para a organização das datas do início dos mutirões, bem como o roteiro dos mesmos.

Através de uma dinâmica com a finalidade de construir a história de como eram feitos os primeiros tratamentos de dejetos humanos se contou com os saberes das famílias agricultoras. À medida que os envolvidos iam dialogando o desenho ia se formando no quadro-branco.

Essa técnica permitiu uma descontração entre os participantes, haja vista que é uma história comum a todos. Nesse momento, recapitulou-se o que foi apresentado sobre o processo de instalação do reator e que se trata de uma tecnologia social desenvolvida para saneamento básico no meio rural.

Outro recurso que se utilizou, para facilitar a apreensão de conteúdos teóricos sobre a tecnologia social apresentada, foi a elaboração e distribuição de uma cartilha impressa, na qual contêm as etapas passo-a-passo como instalar os reatores, pois essa ação tem o objetivo de fortalecer os ofícios do saber e do fazer a tecnologia na sua comunidade, sendo que a cada 
mutirão esse ofício fora reforçado. Também foi confeccionado um banner para que a visualização das etapas de construção da tecnologia social por ser um recurso que auxilia a apreensão visual.

A comunidade escolhida para iniciar a execução do projeto foi a Linha Adolfo Ziguelli onde seis famílias foram beneficiárias. A primeira etapa foi uma ação denominada "demonstração de método" onde foram explicados todos os passos da implantação da tecnologia social, seu funcionamento e os materiais utilizados, sendo que a mão-de-obra coletiva se fez necessária.

A interação dialógica entre os educadores e o público-alvo contribuiu no processo de geração de conhecimento, concebido como um processo de educação coletiva. Importante destacar que, após cada prática demonstrativa, os participantes se reuniam para planejarem a próxima instalação da tecnologia social.

A abordagem da Educação Ambiental no emprego de uma tecnologia social é importante, pois os sujeitos discutem coletivamente os problemas e consensuam soluções, facilitando o retorno dessas informações para a sua comunidade, uma vez que "a Educação Ambiental traz consigo uma nova pedagogia que surge da necessidade de orientar a educação dentro do contexto social e na realidade ecológica e cultural onde se situam os sujeitos e atores do processo educativo." (LEFF, 2001, p. 257).

À medida que o processo de implantação dos reatores iniciava, era possível fazer uma análise da situação encontrada e da situação final que já demonstrava seus efeitos positivos como a elevação da autoestima dos envolvidos por estarem cumprindo sua parte e contribuindo para um desenvolvimento rural sustentável.

Assim que todas as etapas do engenho foram efetivadas, sugeriu-se que as famílias agricultoras realizassem o ajardinamento em torno do reator com o plantio de grama por ser um local passível do lazer das famílias, pois não lhes oferece riscos tampouco odor.

A sugestão do uso desse espaço se deu por ser também um espaço da família e que não haveria problemas de transformá-lo em lazer, já que em muitas propriedades a construção do reator se deu próxima à habitação.

Como meio de verificação foram feitos: registros fotográficos; captação de imagens para produção de um vídeo educativo demonstrando a instalação da tecnologia social; confecção de cartilha e banner; atas e listas de presenças. Também é importante ressaltar que todas as famílias agricultoras participantes do projeto assinaram um termo de consentimento autorizando a divulgação de todos os registros feitos, assim como de participarem da pesquisa.

\section{Avaliação e feedback}

O diálogo que começa a se estabelecer entre Educação Ambiental e tecnologia social tornase uma possível ferramenta para o exercício da cidadania, sendo que as tecnologias sociais são uma estratégia que podem facilitar a interação de múltiplos atores no fortalecimento da Educação Ambiental, proporcionando aprendizagens e construções de cooperação e solidariedade, através de discussões, troca de ideias e de experiências, pesquisas e planejamentos participativos.

Também o trabalho participativo e a troca de saberes entre o pesquisador e o grupo estabeleceram uma relação entre o conhecimento popular e o científico que garante sentido social à produção de conhecimentos e à ação educativa. É na mudança do agir e do pensar que se constroem bases sólidas para a construção coletiva da realidade e se buscam soluções para os problemas comuns a todos. Corroborando com essa ideia, Capra (2006) destaca que "há soluções 
para os principais problemas de nosso tempo, algumas delas até mesmo simples. Mas requerem uma mudança radical em nossas percepções" (CAPRA, 2006, p. 23).

$O$ trabalho realizado teve a participação direta das famílias no processo de construção da tecnologia social e a atribuição do papel de multiplicadores da tecnologia social às outras famílias das comunidades.

A participação da comunidade também foi considerada como componente importante e norteador do processo metodológico e foram estimuladas, durante todo o processo, as práticas organizadas coletivamente incentivando a sua mobilização para melhorar as condições de saneamento ambiental e assegurar a proteção e promoção da saúde e do ambiente.

Foram elaborados produtos para auxiliar na fixação dos conteúdos como uma cartilha impressa contendo imagens com o passo-a-passo da instalação da tecnologia social e um banner também com imagens para orientar no momento da instalação. Também foram captadas imagens para edição de um vídeo que serve como material educativo para escolas e futuros projetos nesse tema. Desse projeto também resultou na produção científica de uma monografia de especialização e artigos publicados em revistas científicas. Essas produções também são acessíveis aos agricultores familiares - atores diretos no projeto, através de cópias entregues na Prefeitura de Bandeirante e também estão disponíveis na internet através de busca pela autora.

Destarte, as etapas metodológicas consistiram de: (i) conhecimento da realidade local; (ii) sensibilização dos atores envolvidos; (iii) implementação de ações práticas e educativas que possibilitam ações sustentáveis; (iv) devolução dos resultados às famílias abrangidas pelo projeto.

Consideraram-se, para escolha do método de pesquisa, os questionamentos, os objetivos e o referencial teórico, o que conduziu à pesquisa-ação, que visa entre outros fins uma interação entre teoria e prática, entre pesquisador e pesquisado, entre os meios e os fins.

Todas as ações realizadas poderão ser tomadas como referência positiva porque as atividades em Educação Ambiental possibilitaram a compreensão dos fundamentos da tecnologia social para o tratamento de esgotos domésticos, constituindo-se em estratégia para sustentabilidade dessa tecnologia.

Daí se conclui que a aliança entre o saneamento ambiental e a Educação Ambiental é fundamental como estratégia nas atuais abordagens das questões de saúde pública, sem a qual os programas e/ou projetos, bem como tecnologias sociais, não alcançam sucesso e não se sustentam.

\section{CONCLUSÃO}

O estudo aqui desenvolvido com agricultores familiares caracterizou-se como um projeto de Educação Ambiental que priorizou a participação dos sujeitos e demonstrou que os problemas diagnosticados em relação à falta de tratamento adequado de esgoto doméstico foram minimizados com o emprego de tecnologia social - reator anaeróbio.

Esta experiência oportunizou a visualização de possibilidades no encontro desses dois campos de conhecimentos: Educação Ambiental e tecnologias sociais; e proporcionou um panorama dos interesses e preocupações ambientais advindos das famílias agricultoras quanto aos danos causados ao meio e as soluções buscadas coletivamente para minimizar esses impactos negativos causados pelo destino inadequado dado aos dejetos domésticos.

O trabalho em grupos foi necessário para desenvolver a capacidade de participação e inserção dos indivíduos no meio social. Importante relatar que os mutirões foram organizados por 
proximidade das propriedades familiares, sendo assim houve maior participação dos membros das famílias. Outrossim, outro ponto pertinente de expor é que as refeições foram feitas de forma solidária e coletiva na propriedade da família onde estava sendo feito o mutirão.

O conhecimento da realidade local foi traçado a partir de dados levantados "in loco" através de contatos diretos com as famílias agricultoras mediante pesquisa domiciliar e pesquisaação.

Os conhecimentos produzidos por este processo investigativo não só identificaram problemas ambientais, mas também potencialidades como a organização social dos agricultores familiares em dialogar com outros atores para juntos buscarem alternativas para minimizarem problemas locais, mas que também é global.

Nas comunidades estudadas, além da mudança na paisagem, instaurou-se uma prática de ações sanitário-ambientais institucionalizadas e de interlocução entre o poder público e a população, pois há outras famílias que solicitaram a implantação de um projeto semelhante a esse.

Essas medidas resultaram na conquista de melhores condições de saneamento, em maior grau de conscientização das comunidades, na noção de cidadania, de direito à saúde e a um ambiente mais saudável, essenciais para a promoção da saúde e para a sustentabilidade da qualidade ambiental do meio rural.

Pertinente destacar que essa pesquisa resultou numa maior aproximação entre a comunidade acadêmica e a população, possibilitando a criação de estratégias para trabalhar tais questões, que configuram metodologias replicáveis a outras realidades semelhantes.

Com base nos princípios da Educação Ambiental - participação, pensamento críticoreflexivo, sustentabilidade, ecologia de saberes, responsabilidade, continuidade, igualdade, conscientização, coletividade, emancipação e transformação social, que são norteadores para quaisquer ações educativas, proporcionou a construção de uma nova concepção de ambiente e de um novo cidadão: reflexivo, solidário e consciente de que pode perceber-se capaz de lutar por um mundo mais justo e sustentável.

Os resultados contribuíram para a melhoria da qualidade de vida através do tratamento adequado do esgoto nas comunidades rurais, bem como das ações e práticas de Educação Ambiental, as quais permitem aos agricultores perceber a realidade e as mudanças, levando-os ao entendimento de uma efetiva emancipação.

Por fim, acredita-se que difundir conhecimentos sob os princípios da educação popular e uso de metodologias participativas e estimular a agricultores familiares ações de Educação Ambiental voltadas para o uso e conservação de recursos naturais, bem como a adoção de tecnologias sociais que busquem minimizar ações antrópicas contribui para a melhoria da qualidade de vida por meio da solidariedade, emancipação e uso racional dos recursos naturais, e efetiva o desenvolvimento rural sustentável.

Realizar a pesquisa foi gratificante por conhecer melhor a realidade dos agricultores familiares, por vivenciar a simplicidade da vida no campo, por receber carinho, amor/diálogo (Paulo Freire) e por perceber a grandiosidade das pequenas ações quando se age coletivamente para transformar realidades. 


\section{REFERÊNCAS BIBLIOGRÁFICAS}

CAPRA, F. As conexões ocultas: ciência para uma vida sustentável. São Paulo: Cultrix, 2005.

. A Teia da Vida: uma nova compreensão científica dos sistemas vivos. São Paulo: Cultrix, 2006.

CERATI, T. M.; LAZARINI, R. A. de M. A pesquisa-ação em educação ambiental: uma experiência no entorno de uma unidade de conservação urbana. Ciência \& Educação, v. 15, n. 2, p. 383-92, 2009. Disponível em:<http://www.cienciamao.usp.br/tudo/exibir.php?midia=rced\&cod=_apesquisa-acaoemeducacao>. Acesso em: 2 nov. 2010.

DIAS, G. F. Iniciação à Temática Ambiental. São Paulo: Gaia, 2004.

FREIRE, P. Extensão ou Comunicação? 5. ed. Rio de Janeiro: Paz e Terra, 1980.

. A educação e mudança. Rio de Janeiro: Paz e Terra, 1981.

. A educação como prática da liberdade. 26. ed. Rio de Janeiro: Paz e Terra, 2002.

. Pedagogia do oprimido. Rio de Janeiro: Paz e Terra, 2005.

GAMBOA, S. A. S. Análise epistemológica dos métodos na pesquisa educacional: um estudo sobre as dissertações de mestrado em educação da UnB. Brasília: Faculdade de Educação UnB, 1982.

INSTITUTO BRASILEIRO DE GEOGRAFIA E ESTATíSTICA. Unidades da Federação. Santa Catarina. Bandeirante. Disponível em:<www.ibge.gov.br>. Acesso em: 25 ago. 2010.

JACOBI, P. Educação Ambiental, cidadania e sustentabilidade. Cadernos de Pesquisa, n. 118, mar. 2003. Disponível em: <http://www.scielo.br/pdf/cp/n118/16834.pdf>. Acesso em: 15 jun. 2009.

LEFF, E. Saber Ambiental: sustentabilidade, racionalidade, complexidade, poder. Rio de Janeiro: Vozes, 2001.

MORIN, E. A Cabeça bem-feita - repensar a reforma, reformar o pensamento. Trad. Eloá Jacobina. Rio de Janeiro: Bertrand Brasil, 2003.

MELO NETO, J. F. de. Pesquisa-Ação. Aspectos práticos da pesquisa-ação nos movimentos sociais populares e em extensão popular.

Disponível em:<http://www.prac.ufpb.br/copac/extelar/producao_academica/artigos/pa_a_pesquisa_acao.pdf>. Acesso em: 20 out. 2010.

PISONI, E. M. A educação ambiental e gênero como instrumentos do desenvolvimento rural em municípios de RS. 2009. 338f. Dissertação (Mestrado em Desenvolvimento Rural) - Universidade Federal do Rio Grande do Sul, Porto Alegre, 2009.

RATTNER, H. Meio Ambiente, saúde e desenvolvimento sustentável. In: Ciência \& Saúde Coletiva, 2009. Disponível em: <http://www.scielo.br/pdf/csc/v14n6/02.pdf>. Acesso em: 15 mai. 2009.

SILVA, G.H. R.; NOUR, E. A. A. Reator compartimentado anaeróbio/aeróbio: sistema de baixo custo para tratamento de esgoto de pequenas comunidades. Revista Brasileira de Engenharia Agrícola e Ambiental, v.9, n. 2, p. 268-275, 2005.

TEIXEIRA, A. C. Educação Ambiental: caminho para a sustentabilidade. Revista Brasileira de Educação Ambiental, n.2, Brasília, DF, 2007. Disponível em: <http://www.ufmt.br/remtea/revbea/pub/revbea_n_2.pdf>. Acesso em: 23 abr. 2010.

THIOLLENT, M. Pesquisa-Ação em Organizações. São Paulo: Atlas, 1997.

TONETTI, et al. Revista Brasileira de Engenharia Agrícola e Ambiental, v.14, n.2, p.227-23, Campina Grande, PB, UAEA/UFCG. Disponível em: <http://www.agriambi.com.br>. Acesso em: 5 out. 2010.

TOZZONI-REIS, M. F. C. Pesquisa-Ação: compartilhando saberes; Pesquisa e Ação educativa ambiental. In: Encontros e Caminhos: formação de educadoras (es) ambientais e coletivos educadores. Brasília: MMA, 2005. 